\title{
QUANTIFICAÇÃO DAS ÁREAS DE PRESERVAÇÃO PERMANENTE E DE RESERVA LEGAL EM PROPRIEDADES DA BACIA DO RIO POMBA-MG ${ }^{1}$
}

Laércio Antônio Gonçalves Jacovine ${ }^{2}$, João Batista Lúcio Corrêa ${ }^{3}$, Márcio Lopes da Silva², Sebastião Renato Valverde ${ }^{2}$, Elpídio Inácio Fernandes Filho ${ }^{4}$, France Maria Gontijo Coelho ${ }^{5}$ Haroldo Nogueira de Paiva ${ }^{2}$

\begin{abstract}
RESUMO - Para a efetivação das áreas de preservação permanente (APPs) e de reserva legal (ARL) nas propriedades rurais, dando cumprimento à legislação, é de extrema importância que elas sejam quantificadas, determinandose o porcentual que ocupam nas propriedades e o que representam essas áreas na atividade econômica dos produtores rurais. Dessa forma, este trabalho teve por objetivo quantificar as APPs e ARL com relação à área total das propriedades rurais pesquisadas. Determinaram-se também a área com vegetação nativa em cada propriedade e as APPs que estavam de acordo com a legislação. Utilizou-se de uma amostra composta por 47 propriedades, divididas em seis estratos, tendo como critério de estratificação o tamanho da área de cada uma delas. A coleta de dados foi realizada com o uso de GPS e a quantificação, com a utilização do SIG ArcView 3.3. Com base nos resultados, observou-se que as 47 propriedades estudadas ocupavam uma área de 1.854 .35 ha, dos quais 811,35 ha, referentes a 43,75\% do total, eram APPs e ARLs, de acordo com as legislações federal e estadual. Além disso, em apenas $21,09 \%$ dessas áreas não ocorria o uso indevido do solo, evidenciandose o não-cumprimento da lei e a necessidade de medidas efetivas para a sua adequação.
\end{abstract}

Palavras-chave: Áreas de preservação permanente, área de reserva legal e legislação ambiental.

\section{QUANTIFICATION OF PERMANENT PRESERVATION AND LEGAL RESERVE AREAS IN RIO POMBA WATERSHED PROPERTIES IN MINAS GERAIS}

\begin{abstract}
Aiming at rendering effective the permanent preservation areas (PPAs) and legal reserve areas (LRA) in the rural properties to fulfill the legislation, it is extremely important to quantify and determine the percentage occupied by these areas in the rural properties as well as the role they play in the economic activities of the farmers. Thus, this project aimed to quantify the PPAs and LRA regarding the total area of the investigated rural properties. The existing area with native vegetation was also determined in each property and in the PPAs in compliance with the legislation. The sample was composed by 47 properties, stratified in six strata and using as a stratification criterion the size of each one of them. Data were collected using a GPS and quantification using the GIS ArcView 3.3. Based on the results, it was verified that the 47 studied properties occupy an area of $1.854 .35 \mathrm{ha}$, of which, $811.35 \mathrm{ha}$, referring to the $43.75 \%$ of the total, are APPs and ARLs, in compliance with the federal and state legislations. Moreover, only $21.09 \%$ of these areas show an appropriate land use, evidencing a non-fulfillment of the law and the need to implement effective corrective measures.
\end{abstract}

Keywords: Permanent preservation areas, legal reserve area and environmental legislation.

\footnotetext{
${ }^{1}$ Recebido em 13.12.2006 e aceito para publicação em 20.02.2008.

${ }^{2}$ Departamento de Engenharia Florestal da Universidade Federal de Viçosa (UFV). E-mail: <jacovine@ufv.br $>$.

${ }^{3}$ Programa de Pós-Graduação em Ciência Florestal da UFV. E-mail: <bcorrea@ rdfnet.com.br>.

${ }^{4}$ Departamento de Solos da UFV. E-mail: <elpidio@ufv.br>.

${ }^{5}$ Departamento de Economia Rural da UFV. E-mail: <fmcoelho@ufv.br>.
} 


\section{INTRODUÇÃO}

A expansão das fronteiras agrícolas, motivada pela necessidade crescente de produzir alimentos em quantidades cada vez maiores, promoveu a derrubada de importantes áreas de florestas para implantação de empreendimentos agropecuários.

O declínio da produtividade agrícola, aliado a uma visão míope da abundância dos recursos naturais, força, continuamente, a conversão de mais e mais terras para a agricultura, deixando um rastro de áreas degradadas (RIBEIRO et al., 2005). Hoje, após décadas de crescimento econômico sem se importar com a conservação dos recursos naturais, o homem percebe que algumas áreas desmatadas para dar lugar a empreendimentos agropecuários não podem continuar desprotegidas, sem uma cobertura vegetal que permita que elas cumpram com suas funções ambientais.

A legislação ambiental foi criada, e vem sendo aperfeiçoada, para que o meio ambiente seja protegido, e os cidadãos possam exigir essa atitude do poder público e também de outros cidadãos. Foram instituídas leis para proteger ambientes frágeis ou especiais, pelas suas características e sua importância ecológica, visando garantir o direito de todos ao ambiente saudável e equilibrado.

Para promover a preservação das florestas e demais formas de vegetação no território brasileiro, o Código Florestal (Lei 4.771/65) instituiu as Áreas de Preservação Permanente (APPs), nas quais a vegetação nativa, seja pela sua função protetora, seja por sua relevância ecológica, deve ser mantida em sua integridade, sendo vedada qualquer exploração econômica. A Medida Provisória no 2166.67/01, que acrescentou o inciso II, do $\S 2^{\circ}$, ao Art. $1^{\circ}$ da Lei Federal 4.771/65, define as APPs como as áreas protegidas nos termos dos Arts. $2^{\circ}$ e $3^{\circ}$ dessa lei, cobertas ou não por vegetação nativa, com a função ambiental de preservar os recursos hídricos, a paisagem, a estabilidade geológica, a biodiversidade e o fluxo gênico de flora e fauna; proteger o solo; e assegurar o bem-estar das populações humanas. Distinguem-se das áreas de "Reserva Legal", também definidas no mesmo Código, por não serem objeto de exploração de nenhuma natureza, como pode ocorrer no caso da Reserva Legal, a partir de um planejamento de exploração sustentável.
A Área de Reserva Legal (20\% da área da propriedade nas Regiões Sul e Sudeste) é considerada de grande importância para a conservação e reabilitação dos processos ecológicos, conservação da biodiversidade e abrigo e proteção da fauna e flora nativas.

Apesar de as APPs e ARL serem protegidas por leis desde a promulgação do Código Florestal em 1965, sabe-se que o desrespeito à legislação é generalizado em todo o país, por isso, devido à importância ambiental dessas áreas, torna-se necessário conhecer todos os possíveis obstáculos à sua efetivação.

A significativa porção da propriedade ocupada pelas áreas de preservação permanente e de reserva legal, aliada ao fato de que as APPs de margens de cursos d'água e em torno de nascentes ocupam a parte mais produtiva da propriedade, torna-se forte barreira ao cumprimento da lei, principalmente em regiões caracterizadas por relevo montanhoso e com marcante presença de nascentes e cursos d'água. Apesar da importância do problema, existem poucos estudos acerca do tema que podem subsidiar os órgãos legisladores e reguladores. Dessa forma, este trabalho teve como objetivos identificar e quantificar as APPs e ARL em propriedades da sub-bacia do rio Pomba, em Minas Gerais.

\section{MATERIAL E MÉTODOS}

\section{1. Área de estudo}

As propriedades pesquisadas localizam-se na Zona da Mata mineira, microrregião mata de Ubá, sub-bacia do rio Pomba, Município de Rio Pomba, em região com altitude máxima de 910 m e mínima de 419 m, apresentando temperatura média máxima anual de $27,9^{\circ}$ e média mínima anual de $15,3^{\circ}$. O relevo dessa área é fortemente acidentado, caracterizando-se por ser $20 \%$ plano, $30 \%$ ondulado e $50 \%$ montanhoso. O clima, segundo a classificação de Köppen, é do tipo Cwb, ou seja, tropical de altitude, na nascente e Cwa, ou seja, tropical quente úmido, no restante da área da bacia (CEIVAP, 2006), sendo a principal atividade econômica rural a pecuária.

\subsection{Definição e estratificação da amostra}

A primeira referência utilizada com o objetivo de definir a amostra de trabalho foi o Censo Agropecuário de 1995-1996 (IBGE, 2005), que apresentou o Município de Rio Pomba, com 456 propriedades rurais, estratificadas segundo o critério do tamanho da área. 
Considerando que a estratificação das propriedades fornecidas pelo Instituto Brasileiro de Geografia e Estatística (IBGE) não atendia às necessidades deste trabalho, por dividir as propriedades em faixas muito amplas de área total, verificou-se a necessidade de se estabelecer nova estratificação, usando faixas mais estreitas. Para isso, recorreu-se ao banco de dados do Sindicato Rural de Rio Pomba, que forneceu um número total de 469 propriedades associadas, próximo ao número fornecido pelo IBGE.

Foram formados seis estratos, tendo por base a área total de cada propriedade rural, distribuindo nesses estratos as propriedades associadas ao Sindicato Rural de Rio Pomba, conforme apresentado no Quadro 1.

Adotou-se a amostragem estratificada proporcional, já que, através dos dados fornecidos pelo Sindicato Rural de Rio Pomba, tinha-se conhecimento, de antemão, da proporção da população pertencente a cada um. Para Marconi e Lakatos (2002), a estratificação proporcional "protege a representatividade da amostra, ao assegurar que os grupos conhecidos da população sejam representados com justiça na amostra".

Para estabelecer o tamanho de cada estrato da amostra, adotou-se uma intensidade amostral mínima de $10 \%$ em cada um, a exemplo de Oliveira (2003).

\subsection{Coleta de dados com o uso de GPS}

Usando o GPS GARMIM PLUS III, detectou-se que os limites de cada propriedade e dos fragmentos de mata foram percorridos, bem como foram marcadas todas as nascentes.

Esses dados permitiram o conhecimento da área total de cada propriedade, da área com mata em cada uma delas e o mapeamento das nascentes, a fim de conferir a existência dessas nascentes com a base cartográfica do IBGE, possibilitando uma atualização e o cálculo preciso das APPs em torno delas.

\subsection{Softwares utilizados e delimitação das APPs}

Para a transferência desses dados do GPS para o computador, utilizou-se o software GPS TrakeMakerPro. Após a migração dos dados, os arquivos foram salvos em formato ShapeFile, para que pudessem ser manipulados nos softwares ArcView 3.3 e ArcGIS 9.

No desenvolvimento deste trabalho, foi aplicada a Resolução $n^{\circ} 303$, do CONAMA, de 20 de março de 2002 (BRASIL, 2002), que no seu art. $2^{\circ}$ estabelece, entre outras, as seguintes definições:

- "morro - elevação do terreno com cota do topo em relação à base entre 50 m e 300 m e encostas com declividade superior a $30 \%$ na linha de maior declividade."

- "montanha - elevação do terreno com cota do topo em relação à base superior a 300 m."

- "base de morro ou montanha - plano horizontal definido por planície ou superfície de lençol d'água adjacente ou, nos relevos ondulados, pela cota da depressão mais baixa ao seu redor."

Através do SIG ArcView 3.3, foi gerado o Modelo Digital de Elevação Hidrologicamente Consistente (MDEHC).

Morros e montanhas foram identificados através da inversão do MDEHC, transformando os vales em topos de morro e os topos em depressões. Para a determinação da base do morro ou montanha, adotouse como padrão o terraço, ou o leito maior, onde se encontra o curso d'água mais próximo.

Quadro 1 - Estratificação das propriedades rurais no Município de Rio Pomba, MG, segundo a área total Table 1 - Stratification of rural properties in the municipal district of Rio Pomba-MG, according to total area

\begin{tabular}{cccc}
\hline ESTRATO & Área Total (ha) & $\mathrm{N}^{\circ}$ Propriedades & Tamanho da Amostra Estratificada \\
\hline 01 & 0,1 a 1,9 & 36 & 04 \\
02 & 2,0 a 9,9 & 93 & 09 \\
03 & 10 a 29,9 & 172 & 17 \\
04 & 30 a 59,9 & 86 & 09 \\
05 & 60 a 120 & 60 & 06 \\
06 & $>120$ & 22 & 02 \\
\hline
\end{tabular}

Fonte: Sindicato Rural de Rio Pomba, MG. 
Obedecendo aos limites estabelecidos pelo art. $3^{\circ}$ da Resolução 303, do CONAMA, delimitaram-se as APPs situadas em: (APP-1) no terço superior de cada morro ou montanha e nas linhas de cumeada; (APP2) área de $30 \mathrm{~m}$ de cada lado dos rios com até $10 \mathrm{~m}$ de largura, área de $50 \mathrm{~m}$ de cada lado dos rios com mais de $10 \mathrm{~m}$ de largura e área de $50 \mathrm{~m}$ de raio em torno das nascentes.

A determinação das APPs de topos de morro e montanha e de linhas de cumeada, através do SIGArcView 3.3, foi feita manualmente, a partir dos dados de localização dos topos, e calculando a diferença na base das elevações.

A delimitação das APPs em torno das nascentes e ao longo dos cursos d'água foi obtida também no ArcView 3.3, através do comando Create Buffer.

Para a quantificação das Áreas de Reserva Legal (ARLs) exigidas para cada propriedade, tomaram-se como referência o Código Florestal (Lei 4.771/65) e a Lei Estadual 14.309/02.

A Legislação Estadual, no que diz respeito às ARLs, apesar de menos restritiva que a União (Código Florestal), gerando um conflito de competência, tem sido adotada para efeito de demarcação e averbação dessas áreas e, por isso, foi considerada neste trabalho.

\section{RESULTADOS E DISCUSSÃO}

\subsection{Quantificação das Áreas de Preservação Permanente (APPs)}

As categorias de Áreas de Preservação Permanente (APP), de interesse para este estudo, foram divididas em dois grupos, com os objetivos de simplificar e facilitar o entendimento, sendo eles: APP-1, que corresponde à soma das APPs de terço superior de morros e de linhas de cumeada; APP-2, que compreende a soma das APPs de cursos d'água até $10 \mathrm{~m}$ de largura, cursos d'água com largura maior que $10 \mathrm{~m}$ e em torno de nascentes com raio de $50 \mathrm{~m}$.

As APPs de declividades superiores a $45^{\circ}$ foram desconsideradas, já que apresentam valores insignificantes quando se considera separadamente cada propriedade.

R. Árvore, Viçosa-MG, v.32, n.2, p.269-278, 2008

\subsubsection{Quantificação das APPs e ARL nas propriedades do estrato 1}

O estrato 1 é formado por quatro propriedades com área de 0,1 a 1,99 ha. No Quadro 2 é apresentado que as APPs e ARL correspondem a 45,45\% da área total (2,7 ha), e em todas as propriedades ocorre o uso indevido das APPs e, ou, ARLs. ALei Estadual n 14.309/ 02, que dispõe sobre as políticas florestais e de proteção à biodiversidade no Estado de Minas Gerais, permite que propriedades menores que 30 ha, nas quais a soma das APPs e ARL ultrapassa 25\% da área total, computem as APPs no cálculo da ARL. Nesse caso, o total de APPs e ARL exigidos por lei cai para 29,12\%, correspondendo a 1,73 ha, sendo 1,51 ha referente à soma das APPs e 0,22 ha à ARL da propriedade $1 \mathrm{~B}$, a única deste estrato que não pode usufruir o benefício da lei.

É importante observar que as quatro propriedades deste estrato não têm, segundo a legislação, APPs de topos de morros (APP-1).

Com relação às APPs de margens de rios e de nascentes (APP-2), observaram-se valores variados nas propriedades desse estrato. Apesar de uma das propriedades (1B) não apresentar, segundo a legislação, nenhuma APP, as outras têm valores significativos, correspondentes a $20,2 \%, 35,4 \%$ e $44,8 \%$ do total de suas áreas.

Observa-se que, das quatro propriedades que compõem esse estrato (1 A, 1B, 1C, 1D), apenas uma delas (1C) possui alguma área com floresta. No entanto, nenhuma cumpre as exigências da legislação vigente, já que essa floresta não se localiza nas áreas de preservação permanente conforme exige a lei. Assim, essa propriedade tem ARL acima do que é exigido por lei, e há uso indevido das APPs.

Quanto ao cumprimento da legislação no que diz respeito à existência de áreas de reserva legal (ARLs) nessas propriedades, também se constatou a irregularidade da situação. A propriedade 1B, com área de 1,08 ha, que segundo a legislação não possui APPs em seus limites, deveria ter $20 \%$ de sua área com cobertura florestal, correspondente à ARL, o que não acontece. As propriedades 1A, 1C e 1D podem computar as APPs para compor a ARL, sendo beneficiadas pela legislação estadual (Lei 14.309/02). 
Quadro 2 - Quantificação das APPs e ARL nas quatro propriedades do estrato1 (propriedades com área total entre 0,1 e 1,99 ha), no Município de Rio Pomba, MG

Table 2 - Quantification of PPAs and LRA in the 4 properties of stratum 1 (Properties with total area between 0.1 and $1.99 \mathrm{ha}$ ) in the municipal district of Rio Pomba - MG

\begin{tabular}{cccccccccc}
\hline Nome & $\begin{array}{c}\text { Área } \\
\text { (ha) }\end{array}$ & $\begin{array}{c}\text { APP-1 } \\
\text { (ha) }\end{array}$ & $\begin{array}{c}\text { APP-2 } \\
\text { (ha) }\end{array}$ & $\begin{array}{c}\text { APP total } \\
\text { (ha) }\end{array}$ & $\begin{array}{c}\text { APP } \\
(\%)\end{array}$ & $\begin{array}{c}\text { ARL } \\
\text { (ha) }\end{array}$ & $\begin{array}{c}\text { APP + ARL } \\
(\%)\end{array}$ & $\begin{array}{c}\text { Floresta } \\
\text { (ha) })\end{array}$ & $\begin{array}{c}\text { UI } \\
\text { (ha) }\end{array}$ \\
\hline 1A & 0,96 & 0 & 0,43 & 0,43 & 44,8 & 0,19 & 64,80 & 0 & $-0,43$ \\
1B & 1,08 & 0 & 0 & 0 & 0 & 0,22 & 20,37 & 0 & $-0,22$ \\
1C & 1,92 & 0 & 0,68 & 0,68 & 35,4 & 0,38 & 55,40 & 0,74 & $-0,68^{*}$ \\
1D & 1,98 & 0 & 0,40 & 0,40 & 20,2 & 0,40 & 40,20 & 0 & $-0,40$ \\
\hline Total & 5,94 & 0 & 1,51 & 1,51 & 25,42 & 1,19 & 45,45 & 0,74 & $-1,73$ \\
\hline
\end{tabular}

APP-1 = terço superior dos morros mais linhas de cumeada. APP-2 = margens de rios, córregos e em torno de nascentes. $\mathrm{ARL}=$ área de reserva legal $(20 \%$ da área da propriedade $)$. Floresta = área de floresta existente na propriedade. UI = APPs e ARLs com uso indevido. ${ }^{*}=$ a área de floresta não se localizava em APP.

Fonte: dados da pesquisa.

\subsubsection{Quantificação das APPs e ARL nas propriedades do estrato 2}

O estrato 2 consta de nove propriedades rurais com área de 2 a 9,9 ha. No Quadro 3, é mostrado que nesse estrato a soma das áreas das propriedades corresponde a 54,12 ha, onde se têm 8,99ha de APP1 (topo de morro) e 10,21 ha de APP-2 (água). Assim, tem-se que, em média, 35,70\% da área total desse estrato é considerada como APPs.

Com relação à área de reserva legal (ARL), nas nove propriedades desse estrato observou-se que oito delas têm a soma das APPs e ARL ultrapassando 25\% da área total, o que permite, segundo a legislação estadual, computar as APPs no cálculo da ARL. Desse modo, a área de reserva legal (ARL) deixa de ter importância quanto à ocupação de área e de possível impacto econômico.

Analisando individualmente, observa-se que cinco dessas propriedades (2A, 2B, 2C, 2E e $2 \mathrm{~F}$ ) não possuem a categoria de APP-1 (topo de morro). Das restantes, três apresentam valores expressivos para essa categoria de $\operatorname{APP}(2 \mathrm{D}, 2 \mathrm{G}$ e $2 \mathrm{I})$.

No que se refere à categoria de APP-2 (água), apenas três $(2 \mathrm{C}, 2 \mathrm{D}$ e $2 \mathrm{I})$ das nove propriedades desse estrato não a apresentam.

Quadro 3 - Quantificação das APPs e ARL nas nove propriedades do estrato 2 (propriedades com área entre 2 ha e 9,9 ha), no Município de Rio Pomba, MG

Table 3 - Quantification of PPAs and LRA in the 9 properties of stratum 2 (Properties with area between 2ha and 9.9ha) in the municipal district of Rio Pomba $-M G$

\begin{tabular}{|c|c|c|c|c|c|c|c|c|c|}
\hline Nome & $\begin{array}{l}\text { Área } \\
\text { (ha) }\end{array}$ & $\begin{array}{l}\text { APP-1 } \\
\text { (ha) }\end{array}$ & $\begin{array}{l}\text { APP-2 } \\
\text { (ha) }\end{array}$ & $\begin{array}{l}\text { APP total } \\
\text { (ha) }\end{array}$ & $\begin{array}{l}\text { APP } \\
(\%)\end{array}$ & $\begin{array}{l}\text { ARL } \\
\text { (ha) }\end{array}$ & $\begin{array}{c}\mathrm{APP}+\mathrm{ARL} \\
(\%)\end{array}$ & $\begin{array}{c}\text { Floresta } \\
\text { (ha) }\end{array}$ & $\begin{array}{c}\text { UI } \\
\text { (ha) }\end{array}$ \\
\hline $2 \mathrm{~A}$ & 2,52 & 0 & 1,41 & 1,41 & 55,95 & 0,50 & 75,95 & 0 & $-1,41$ \\
\hline $2 \mathrm{~B}$ & 2,98 & 0 & 1,06 & 1,06 & 35,6 & 0,60 & 55,70 & 0 & $-1,06$ \\
\hline $2 \mathrm{C}$ & 4,58 & 0 & 0 & 0 & 0 & 0,92 & 20,09 & 0 & $-0,92$ \\
\hline $2 \mathrm{D}$ & 5,24 & 2,86 & 0 & 2,86 & 54,6 & 1,05 & 74,62 & 1,25 & $-1,61$ \\
\hline $2 \mathrm{E}$ & 5,64 & 0 & 0,44 & 0,44 & 7,80 & 1,13 & 27,84 & 0 & $-1,13$ \\
\hline $2 \mathrm{~F}$ & 7,57 & 0 & 1,78 & 1,78 & 23,5 & 1,51 & 43,46 & 0 & - 1,78 \\
\hline $2 \mathrm{G}$ & 7,67 & 1,98 & 3,02 & 5,00 & 65,2 & 1,53 & 85,14 & 0 & $-5,00$ \\
\hline $2 \mathrm{H}$ & 8,77 & 0,76 & 2,50 & 3,26 & 37,2 & 1,75 & 57,12 & 0 & $-3,26$ \\
\hline 2 I & 9,15 & 3,39 & 0 & 3,39 & 37,0 & 1,83 & 57,05 & 0 & $-3,39$ \\
\hline Total & 54,12 & 8,99 & 10,21 & 19,20 & 35,70 & 10,82 & 55,47 & 1,25 & $-19,56$ \\
\hline
\end{tabular}

APP-1 = terço superior dos morros mais linhas de cumeadas. APP-2 = margens de rios, córregos e em torno de nascentes. $\mathrm{ARL}=$ área de reserva legal $(20 \%$ da área da propriedade $) . \mathrm{UI}=\mathrm{APPs}$ e ARL com uso indevido. Floresta $=$ área de floresta na propriedade Fonte: dados da pesquisa. 
Considerando o total das áreas de preservação permanente (APP-1 e APP-2) em cada propriedade desse estrato, apenas uma (2C) apresenta valor zero, enquanto as demais têm valores bem expressivos, chegando uma delas $(2 \mathrm{G})$ a ter $65,2 \%$ de sua área ocupada por APPs.

Observa-se que nas propriedades desse estrato a categoria de APP-2 (água) está ocupando mais áreas do que a categoria de APP-1 (topo de morro), perfazendo 10,21 ha e 8,99 ha, respectivamente.

Nesse estrato, as APPs e ARL correspondem a 55,47\% da área total, ou seja, (30,02 ha), e em todas as propriedades há déficit de APP e, ou, ARL. Considerando a Lei Estadual $n^{\circ} 14.309 / 02$, esse porcentual cai para $38,45 \%$, correspondendo a 20,81 ha, em que 19,20 ha são referentes à soma das APPs, 0,92 ha à ARL da propriedade $2 \mathrm{C}$ e 0,69 ha de complemento à ARL na propriedade $2 \mathrm{E}$.

Observou-se que nenhuma das propriedades cumpre a legislação, no diz respeito tanto às APPs quanto à ARL, visto que a exigência é de 20,81 ha em vegetação nativa e existe apenas 1,25 ha, apresentando um déficit de 19,56 ha a ser efetivado.

\subsubsection{Quantificação das APPs e ARL nas propriedades do estrato 3}

O estrato 3 é formado por 17 propriedades rurais com área de 10 a 29,9 ha. O Quadro 5 representa esse estrato com os dados de área de cada propriedade e as APPs e ARL quantificadas para cada uma delas.

A soma das áreas das propriedades desse estrato perfaz um total de 323,99 ha, enquanto a soma das APPs de todas elas totaliza 129,15 ha, o que corresponde, em média, a 39,86\% de APPs, segundo a legislação vigente.

Nessas propriedades, tanto a categoria de APP1 (topo de morro) quanto a de APP-2 (água) ocupam elevado porcentual de área, ressaltando-se que apenas três propriedades (3E, $3 \mathrm{~F} \mathrm{e} 3 \mathrm{M}$ ) não apresentam, segundo a legislação, a categoria de APP-1 (topo de morro). Nas propriedades 3P e 3I, essa categoria de APP ocupa valores superiores a $50 \%$ da área total da propriedade.

Observa-se, pelo Quadro 4, que o total de APPs em cada propriedade, expresso em porcentagem, revela que apenas três propriedades ( $3 \mathrm{E}, 3 \mathrm{~F}$ e $3 \mathrm{H})$ têm esse valor menor que $25 \%$ e que, no entanto, duas propriedades se destacam, por apresentarem valores maiores que $69 \%$.

Quadro 4 - Quantificação das APPs e ARL nas 17 propriedades do estrato 3 (propriedades com área entre 10 ha e 29,9 ha), no Município de Rio Pomba, MG

Table 4 - Quantification of PPAs and LRA in the 17 properties of stratum 3 (Property area between 10ha and 29.9ha) in the municipal district of Rio Pomba $-M G$

\begin{tabular}{|c|c|c|c|c|c|c|c|c|c|}
\hline Nome & $\begin{array}{l}\text { Área } \\
\text { (ha) }\end{array}$ & $\begin{array}{l}\text { APP-1 } \\
\text { (ha) }\end{array}$ & $\begin{array}{l}\text { APP-2 } \\
\text { (ha) }\end{array}$ & $\begin{array}{l}\text { APP total } \\
\text { (ha) }\end{array}$ & $\begin{array}{l}\text { APP } \\
(\%)\end{array}$ & $\begin{array}{l}\text { ARL } \\
\text { (ha) }\end{array}$ & $\begin{array}{c}\mathrm{APP}+\mathrm{ARL} \\
(\%)\end{array}$ & $\begin{array}{c}\text { Floresta } \\
\text { (ha) }\end{array}$ & $\begin{array}{c}\text { UI } \\
\text { (ha) }\end{array}$ \\
\hline $3 \mathrm{~A}$ & 11,30 & 3,20 & 1,91 & 5,11 & 45,22 & 2,26 & 65,22 & 5,08 & $-1,91$ \\
\hline $3 \mathrm{~B}$ & 11,40 & 2,65 & 1,36 & 4,01 & 35,20 & 2,28 & 55,20 & 0 & $-4,00$ \\
\hline $3 C$ & 11,84 & 2,40 & 2,74 & 5,14 & 43,42 & 2,37 & 63,42 & 0 & $-5,14$ \\
\hline $3 \mathrm{D}$ & 12,70 & 0,39 & 2,78 & 3,17 & 25,00 & 2,54 & 45,00 & 0,97 & $-2,20$ \\
\hline $3 E$ & 13,66 & 0 & 2,30 & 2,30 & 16,90 & 2,73 & 36,90 & 0 & $-2,30$ \\
\hline $3 F$ & 17,01 & 0 & 0,12 & 0,12 & 0,70 & 3,40 & 20,70 & 0 & $-3,52$ \\
\hline $3 G$ & 17,21 & 5,58 & 4,32 & 9,90 & 57,51 & 3,44 & 77,51 & 3,39 & $-6,51$ \\
\hline $3 \mathrm{H}$ & 18,57 & 0,39 & 1,16 & 1,55 & 8,32 & 3,71 & 28,32 & 1,20 & $-0,35$ \\
\hline $3 \mathrm{I}$ & 19,70 & 10,44 & 4,22 & 14,66 & 74,44 & 3,94 & 94,44 & 2,09 & $-12,57$ \\
\hline $3 \mathbf{J}$ & 20,07 & 0,11 & 7,91 & 8,02 & 40,00 & 4,01 & 60,00 & 0 & $-8,02$ \\
\hline $3 \mathrm{~L}$ & 20,52 & 5,43 & 2,81 & 8,24 & 40,02 & 4,10 & 60,20 & 1,80 & $-6,44$ \\
\hline $3 \mathrm{M}$ & 22,91 & 0 & 7,93 & 7,93 & 34,60 & 4,58 & 54,60 & 0 & $-7,93$ \\
\hline $3 \mathrm{~N}$ & 23,54 & 7,80 & 2,30 & 10,10 & 42,90 & 4,71 & 62,90 & 2,86 & $-7,24$ \\
\hline 30 & 23,81 & 6,58 & 3,50 & 10,08 & 42,33 & 4,76 & 62,33 & 1,92 & $-8,16$ \\
\hline $3 \mathrm{P}$ & 24,75 & 13,52 & 3,61 & 17,13 & 69,20 & 4,94 & 89,20 & 4,80 & $-12,33$ \\
\hline $3 Q$ & 26,90 & 7,85 & 3,67 & 11,52 & 42,8 & 5,38 & 62,80 & 1,32 & $-10,20$ \\
\hline $3 \mathrm{R}$ & 28,10 & 3,52 & 6,65 & 10,17 & 36,20 & 5,62 & 56,20 & 0 & $-10,17$ \\
\hline Total & 323,99 & 69,86 & 59,29 & 129,15 & 39,86 & 64,77 & 59,85 & 25,43 & 108,99 \\
\hline
\end{tabular}

Floresta $=$ área de floresta na propriedade. UI = APPs e ARL com uso indevido. Fonte: dados da pesquisa.

R. Árvore, Viçosa-MG, v.32, n.2, p.269-278, 2008 
Prevalece nas propriedades desse estrato o mesmo benefício usufruído pelas propriedades dos estratos anteriores, devido à Lei Estadual no 14.309/02. Desse modo, apesar de a soma das APPs e ARLs corresponder a 59,85\% dos 323,99 ha desse estrato, pela legislação estadual o porcentual exigido em cobertura por vegetação nativa cai para $40,91 \%$. De um total de 132,55 ha, 129,15 ha correspondem à soma das APPs e 3,40 ha, à ARL da propriedade $3 \mathrm{~F}$, a única que não pode computar as APPs no cálculo da ARL, perfazendo um total de 132,55 ha.

Quanto à situação dessas propriedades perante a lei, no que diz respeito às APPs observou-se o descumprimento da legislação por todas elas, em que em sete dessas propriedades não existia nenhuma área com mata ou outro tipo de vegetação nativa. Somente a propriedade $3 \mathrm{~A}$ possuía área com mata $(5,08$ ha) próxima ao que exige a lei $(5,11 \mathrm{ha})$, no entanto essa mata se concentra toda nos topos dos morros. Nesse caso, ainda há a necessidade de ser destinado 1,91 ha para a efetivação das APPs em torno da nascente e do córrego que passa por ela.

Quanto à ARL, observou-se que a única propriedade que necessita de efetivar essa área fora das APPs (propriedade 3F) não tinha nenhum fragmento de floresta.

O descumprimento da legislação foi também observado pela presença de apenas 25,43 ha com floresta, permanecendo um déficit de 108,99 ha.

\subsubsection{Quantificação de APPs e ARL nas propriedades do estrato 4}

O estrato 4 é formado por nove propriedades rurais com área de 30 a 59,9 ha. O Quadro 5 representa esse estrato com os dados de área de cada propriedade e as APPs e ARL quantificadas para cada uma delas.

A soma das áreas das propriedades desse estrato perfaz um total de 363,24 ha, dos quais 102,74 ha são da categoria de APP-1 (topo de morro) e 62,50 ha da categoria de APP-2 (água), perfazendo um total de 165,24 ha de APPs, o que corresponde a 45,49\% da área total desse estrato, segundo a legislação vigente.

A soma das APPs e ARL nesse estrato corresponde a $65,49 \%$ da sua área total. No entanto, considerando a Lei 14.309/02, que dispõe sobre políticas florestais no Estado de Minas Gerais, segundo a qual as propriedades maiores que 30 ha, cuja soma das APPs e ARL ultrapassa $50 \%$ da área total, podem computar as APPs no cálculo da ARL; esse porcentual cai para $47,51 \%$ da área total, já que somente a propriedade 4C necessita efetivar a ARL fora das APPs.

Esse estrato deveria ter 172,57 ha em área com vegetação nativa, referente a 165,24 ha de APPs mais 7,33 ha de ARL da propriedade $4 \mathrm{C}$, no entanto tem apenas 23,66 ha com floresta, apresentando um déficit de 148,91 ha.

Quadro 5 - Quantificação das APPs e ARL das nove propriedades do estrato 4 (propriedades com área entre 30 ha e 59,9 ha), no Município de Rio Pomba, MG

Table 5 - Quantification of PPAs and LRA of the 9 properties of stratum 4 (Property area between 30ha and 59.9ha) in the municipal district of Rio Pomba $-M G$

\begin{tabular}{|c|c|c|c|c|c|c|c|c|c|}
\hline Nome & $\begin{array}{l}\text { Área } \\
\text { (ha) }\end{array}$ & $\begin{array}{l}\text { APP-1 } \\
\text { (ha) }\end{array}$ & $\begin{array}{l}\text { APP-2 } \\
\text { (ha) }\end{array}$ & $\begin{array}{l}\text { APP total } \\
\text { (ha) }\end{array}$ & $\begin{array}{l}\text { APP } \\
(\%)\end{array}$ & $\begin{array}{l}\text { ARL } \\
\text { (ha) }\end{array}$ & $\begin{array}{c}\mathrm{APP}+\mathrm{ARL} \\
(\%)\end{array}$ & $\begin{array}{c}\text { Floresta } \\
\text { (ha) }\end{array}$ & $\begin{array}{c}\text { UI } \\
\text { (ha) }\end{array}$ \\
\hline $4 \mathrm{~A}$ & 33,53 & 6,79 & 5,49 & 12,28 & 36,6 & 6,71 & 56,60 & 0,78 & $-11,50$ \\
\hline $4 B$ & 34,27 & 4,73 & 6,33 & 11,06 & 32,3 & 6,85 & 52,30 & 3,45 & $-7,61$ \\
\hline $4 \mathrm{C}$ & 36,66 & 2,71 & 2,58 & 5,29 & 14,4 & 7,33 & 34,40 & 4,36 & $-8,26$ \\
\hline $4 \mathrm{D}$ & 37,55 & 22,58 & 6,95 & 29,53 & 78,6 & 7,51 & 98,60 & 3,80 & $-25,73$ \\
\hline $4 \mathrm{E}$ & 38,61 & 8,52 & 5,72 & 14,24 & 36,9 & 7,72 & 56,90 & 0 & $-14,24$ \\
\hline $4 \mathrm{~F}$ & 38,64 & 17,06 & 7,39 & 24,45 & 63,3 & 7,73 & 83,30 & 0 & $-24,45$ \\
\hline $4 \mathrm{G}$ & 38,91 & 5,87 & 8,76 & 14,63 & 37,6 & 7,78 & 57,60 & 2,97 & $-11,66$ \\
\hline $4 \mathrm{H}$ & 49,31 & 28,40 & 7,10 & 35,50 & 72,0 & 9,86 & 55,50 & 3,65 & $-31,85$ \\
\hline $4 \mathrm{I}$ & 55,76 & 6,08 & 12,18 & 18,26 & 32,7 & 11,15 & 52,70 & 4,65 & $-13,61$ \\
\hline Total & 363,24 & 102,74 & 62,50 & 165,24 & 45,49 & 72,64 & 65,49 & 23,66 & $-148,91$ \\
\hline
\end{tabular}

APP-1 = terço superior dos morros mais linhas de cumeadas. APP-2 = margens de rios, córregos e em torno de nascentes $\mathrm{ARL}=$ área de reserva legal $(20 \%$ da área da propriedade $)$. Floresta $=$ área de floresta na propriedade.

$\mathrm{UI}=$ APPs e ARLs com uso indevido. Fonte: dados da pesquisa.

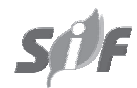

R. Árvore, Viçosa-MG, v.32, n.2, p.269-278, 2008 
As propriedades 4F, 4H e 4D apresentam 44,15\%, $57,6 \%$ e $60 \%$ de APP-1 (topo de morro), respectivamente. Considerando ser essa apenas uma das categorias de APPs, esse valor se torna relativamente elevado. Em função do elevado valor de APP-1, somado à APP2 (água), essas propriedades apresentam 63,3\%, 72\% e $78,6 \%$ do valor total de APPs, respectivamente.

Com relação ao total de APPs em cada propriedade, observou-se que apenas uma delas (4C) apresentou valor menor que $32 \%$.

Conforme observado nas propriedades dos estratos anteriores, estas também se encontram distantes quanto ao cumprimento da legislação, tanto no que diz respeito às APPs quanto à ARL. Nesse estrato, duas propriedades que não têm nenhuma vegetação nativa e as demais apresentam valores insignificantes.

\subsubsection{Quantificação das APPs e ARL nas propriedades do estrato 5}

O estrato 5 é formado por seis propriedades rurais com área de 60 a 119,9 ha. No Quadro 6, apresentase esse estrato com os dados das áreas de cada propriedade.

A soma das áreas das propriedades desse estrato corresponde a 508,26 ha, em que 136,92 ha são da categoria de APP-1 (morro) e 90,16 ha, de APP-2 (água), perfazendo um total de 227,08 ha de APPs. Assim, 44,7\% desse estrato é considerado APPs pela legislação vigente.

A soma das APPs e ARL nesse estrato daria um valor correspondente a $64,7 \%$ da área total do estrato. No entanto, considerando a Lei Estadual n ${ }^{\circ} 14.309 / 02$, esse porcentual cai de $64,7 \%$ para $44,7 \%$ da área total, já que nenhuma das propriedades desse estrato necessita efetivar a ARL fora das APPs, usufruindo, assim, do benefício da lei. Esse estrato deveria ter, portanto, 227,08 ha em área com vegetação nativa, referente às APPs, no entanto tem apenas 34,31 ha com florestas, com um déficit de 192,77 ha.

Todas as propriedades desse estrato apresentam algum fragmento de mata, que varia de 2,95 ha na propriedade 5C, correspondendo a 3,69\% de sua área; e 9,69 ha na propriedade $5 F$, correspondendo a $10,43 \%$ de sua área. Observa-se que são valores relativamente pequenos, considerando o que é exigido por lei.

\subsubsection{Quantificação das APPs e ARL nas propriedades do estrato 6}

O estrato 6 é formado por duas propriedades rurais com área maior que 120 ha. No Quadro 7, representase esse estrato com os dados de área de cada propriedade, bem como as APPs e ARL quantificadas para cada uma delas.

A soma das APPs e ARL nesse estrato daria um valor correspondente a $56,41 \%$ da área total do estrato. No entanto, considerando a Lei Estadual n ${ }^{\circ} 14.309 /$ 02 , esse porcentual cai de $56,41 \%$ para $42,97 \%$ da área total, já que a propriedade $6 \mathrm{~B}$ pode efetivar a ARL dentro das APPs.

Esse estrato deveria ter 257,30 ha em área com vegetação nativa, referente a 218,07 ha de APPs e 39,23 ha de ARL da propriedade $6 \mathrm{~A}$, no entanto tem apenas 90,20 ha com floresta, apresentando um déficit de 168,22 ha.

Quadro 6 - Quantificação das áreas de preservação permanente (APPs) do estrato 5 (propriedades com área entre 60 ha e 119,9 ha), no Município de Rio Pomba, MG

Table 6 - Quantification of permanent preservation areas (PPAs) of stratum 5 (Property area between 60ha and 119.9ha) in the municipal district of Rio Pomba $-M G$

\begin{tabular}{|c|c|c|c|c|c|c|c|c|c|}
\hline Nome & $\begin{array}{l}\text { Área } \\
\text { (ha) }\end{array}$ & $\begin{array}{l}\text { APP-1 } \\
\text { (ha) }\end{array}$ & $\begin{array}{l}\text { APP-2 } \\
\text { (ha) }\end{array}$ & $\begin{array}{l}\text { APP total } \\
\text { (ha) }\end{array}$ & $\begin{array}{l}\text { APP } \\
(\%)\end{array}$ & $\begin{array}{l}\text { ARL } \\
\text { (ha) }\end{array}$ & $\begin{array}{c}\mathrm{APP}+\mathrm{ARL} \\
(\%)\end{array}$ & $\begin{array}{c}\text { Floresta } \\
\text { (ha) }\end{array}$ & $\begin{array}{c}\text { UI } \\
\text { (ha) }\end{array}$ \\
\hline $5 \mathrm{~A}$ & 77,19 & 17,32 & 16,87 & 34,19 & 44,3 & 15,44 & 54,19 & 4,86 & $-29,33$ \\
\hline $5 B$ & 78,20 & 34,34 & 10,39 & 44,73 & 57,2 & 15,64 & 64,73 & 9,68 & $-35,05$ \\
\hline $5 \mathrm{C}$ & 79,95 & 22,24 & 8,39 & 30,63 & 38,3 & 15,99 & 50,63 & 2,95 & $-27,68$ \\
\hline 5D & 87,67 & 15,77 & 17,73 & 33,50 & 38,2 & 17,53 & 53,50 & 3,38 & $-30,12$ \\
\hline $5 \mathrm{E}$ & 92,37 & 11,68 & 24,21 & 35,89 & 38,9 & 18,47 & 55,89 & 3,75 & $-32,14$ \\
\hline $5 \mathrm{~F}$ & 92,88 & 35,57 & 12,57 & 48,14 & 51,8 & 18,58 & 71,83 & 9,69 & $-38,45$ \\
\hline Total & 508,26 & 136,92 & 90,16 & 227,08 & 44,7 & 101,65 & 64,70 & 34,31 & $-192,77$ \\
\hline
\end{tabular}

Floresta = área de floresta na propriedade. UI = APPs e ARL com uso indevido.

Fonte: dados da pesquisa.

R. Árvore, Viçosa-MG, v.32, n.2, p.269-278, 2008 
Quadro 7 - Quantificação das áreas de preservação permanente (APPs) do estrato 6 (propriedades com área maior que 120 ha), no Município de Rio Pomba, MG

Table 7 - Quantification of permanent preservation areas (PPAs) of stratum 6 (Property area bigger than 120ha) in the municipal district of Rio Pomba $-M G$

\begin{tabular}{|c|c|c|c|c|c|c|c|c|c|}
\hline Nome & $\begin{array}{l}\text { Área } \\
\text { (ha) }\end{array}$ & $\begin{array}{l}\text { APP-1 } \\
\text { (ha) }\end{array}$ & $\begin{array}{l}\text { APP-2 } \\
\text { (ha) }\end{array}$ & $\begin{array}{c}\text { APP total } \\
\text { (ha) }\end{array}$ & $\begin{array}{l}\text { APP } \\
(\%)\end{array}$ & $\begin{array}{l}\text { ARL } \\
\text { (ha) }\end{array}$ & $\begin{array}{c}\mathrm{APP}+\mathrm{ARL} \\
(\%)\end{array}$ & $\begin{array}{c}\text { Floresta } \\
\text { (ha) }\end{array}$ & $\begin{array}{c}\text { UI } \\
\text { (ha) }\end{array}$ \\
\hline $6 \mathrm{~A}$ & 196,14 & 12,05 & 22,59 & 34,64 & 17,66 & 39,23 & 37,66 & 52,4 & $-22,59$ \\
\hline $6 \mathrm{~B}$ & 402,66 & 121,38 & 62,05 & 183,43 & 45,15 & 80,53 & 65,55 & 37,8 & $-145,63$ \\
\hline$\overline{\text { Total }}$ & 598,80 & 133,43 & 84,64 & 218,07 & 36,42 & 119,76 & 56,41 & 90,2 & $-168,22$ \\
\hline
\end{tabular}

APP-1 = terço superior dos morros mais linhas de cumeadas. APP-2 = margens de rios, córregos e em torno de nascentes Floresta = área de mata na propriedade. UI = APPs e ARL com uso indevido. Fonte: dados da pesquisa.

As duas propriedades que compõem esse estrato têm área total de 598,80 ha. Desse montante, 218,07 ha são considerados APPs pela legislação, valor que corresponde a $36,42 \%$ do total da área ocupada por elas. Constatou-se que apenas uma delas tem valor expressivo, tanto da classe APP-1 (morro) quanto também a APP-2 (água).

A propriedade $6 \mathrm{~A}$ se diferencia das propriedades de todos os estratos, por apresentar 52,4 ha em floresta, correspondendo a $26,71 \%$ de sua área total. Por isso, ela satisfaz as exigências da legislação, referente à categoria de APP-1 (morro) e à ARL. Permanece, no entanto, com um déficit de 22,59 ha referente à categoria de APP-2 (água). Mesmo assim, essa propriedade se destaca por ser a que mais se aproxima dos valores exigidos pela legislação, no que se refere às APPs e à ARL.

\subsubsection{Quantificação total das APPs}

No Quadro 8, apresenta-se o total de APPs e ARL exigido pela legislação nas 47 propriedades pesquisadas.

Observa-se que, o total de 1.854,35 ha, a legislação exige que sejam efetivados 451,94 ha referente à categoria de APP-1 (morro) e 308,31 ha referente à categoria de APP-2 (água), perfazendo um total de 760,25 ha de APPs, o que corresponde a $41 \%$ da área total das 47 propriedades.

Quadro 8 - Total de APPs e ARL das 47 propriedades pesquisadas em cada um dos estratos, no Município de Rio Pomba, MG Table 8 -Total of PPAs and LRA in the 47 properties analyzed in each strata in the municipal district of Rio Pomba - MG

\begin{tabular}{ccccccccccc}
\hline EST. & Área & $\begin{array}{c}\text { APP-1 } \\
\text { (ha) }\end{array}$ & $\begin{array}{c}\text { APP-2 } \\
\text { (ha) }\end{array}$ & $\begin{array}{c}\text { APP } \\
\text { total } \\
\text { (ha) }\end{array}$ & $\begin{array}{c}\text { APP } \\
\text { total } \\
(\%)\end{array}$ & $\begin{array}{c}\text { ARL } \\
\text { exigida } \\
\text { (ha) }\end{array}$ & $\begin{array}{c}\text { APP+ARL } \\
\text { exigida } \\
\text { (ha) }\end{array}$ & $\begin{array}{c}\text { APP+ARL } \\
\text { exigida } \\
(\%)\end{array}$ & $\begin{array}{c}\text { Floresta } \\
\text { (ha) }\end{array}$ & $\begin{array}{c}\text { UI } \\
\text { (ha) }\end{array}$ \\
\hline 1 & 5,94 & 0 & 1,51 & 1,51 & 25,42 & 0,22 & 1,73 & 29,12 & $0,74^{*}$ & $-1,73$ \\
2 & 54,12 & 8,99 & 10,21 & 19,20 & 35,70 & 0,92 & 20,12 & 38,45 & 1,25 & $-19,56$ \\
3 & 323,99 & 69,86 & 59,29 & 129,15 & 39,86 & 3,40 & 132,55 & 40,91 & $25,43 *$ & $-108,99$ \\
4 & 363,24 & 102,74 & 62,50 & 165,24 & 45,49 & 7,33 & 172,57 & 47,51 & 23,66 & $-148,91$ \\
5 & 508,26 & 136,92 & 90,16 & 227,08 & 44,70 & 0 & 227,08 & 44,70 & 34,31 & $-192,77$ \\
6 & 598,50 & 133,43 & 84,64 & 218,07 & 36,42 & 39,23 & 257,30 & 42,99 & $90,20^{*}$ & $-168,22$ \\
\hline Total & 1854,35 & 451,94 & 308,31 & 760,25 & 41,00 & 51,10 & 811,35 & 43,75 & $175,59^{*}$ & $-640,18$ \\
\hline
\end{tabular}

Estrato $1=4$ propriedades (até 1,99 ha), estrato $2=9$ propriedades (de 2 a 9,9 ha), estrato $3=17$ propriedades (de 10 a 29,9 ha), estrato $4=9$ propriedades (de 30 a 59,9 ha), estrato $5=6$ propriedades (de 60 a 119,9 ha), estrato $6=2$ propriedades (acima de 120 ha).

* = existe fragmento de floresta que, pela sua localização, não pode ser aproveitado para computar as APPs.

ARL exigida = ARL exigida considerando a Legislação Estadual (Lei 14.309/02).

APP + ARL exigida = considerando a legislação estadual.

Floresta $=$ área de floresta em cada estrato.

Fonte: dados da pesquisa. 
Considerando as APPs e os $20 \%$ de ARL, a legislação iria exigir $1.131,12$ ha de vegetação nativa, sendo 760,25 ha referentes às APPs e 370,87 ha às ARL, significando $61 \%$ da área total. Entretanto, como a Lei Estadual $n^{\circ} 14.309 / 02$ permite o cômputo das APPs no cálculo da ARL quando a soma das APPs e ARL ultrapassar $25 \%$ e $50 \%$ em propriedades com área inferior ou igual a 30 ha e propriedades maiores que 30 ha, respectivamente, esse valor cai para 811,35 ha, sendo 760,25 ha referentes às APPs e 51,10 ha à ARL. Desse modo, a efetivação das APPs e ARL para essas 47 propriedades irá ocupar 43,75\% da área total.

Apesar da existência de 175,59 ha de floresta, há um déficit de 640,18 ha para que sejam efetivadas as APPs e ARL. Esse déficit, em alguns estratos, não corresponde à diferença entre o que a legislação exige e há na floresta, já que, em alguns casos, a área florestal nãoatende às exigências da lei quanto à sua localização, não podendo ser aproveitada.

Em todos os estratos, a exigência de ARLé relativamente pequena, devido à Lei Estadual 14.309/02, de tal modo que, no estrato 5, essas áreas não são exigidas em nenhuma das propriedades, já que todas elas podem computar as APPs no cálculo do porcentual da ARL.

Observou-se que em quatro estratos o porcentual de APPs e ARL exigido por lei está acima de $40 \%$ da área total do estrato, evidenciando que a efetivação dessas áreas, nessas propriedades, não é tarefa simples.

\section{CONCLUSÕES}

Do exposto, foi possível concluir que:

- As APPs e ARL correspondiam, em média, a 43,75\% do total das áreas das propriedades estudadas, confirmando a premissa de que na região da Zona da Mata, em razão da sua topografia e abundância de cursos d'água, grande parte das propriedades teria restrições quanto à sua utilização para a pecuária.

- Todas as propriedades pesquisadas estavam em desacordo com a lei, tanto no que diz respeito às APPs quanto à ARL.

- Um baixo porcentual $(21,09 \%)$ do total de APPs e ARLs previstas pela legislação estava sendo atendido nas propriedades.

- As áreas de preservação permanente localizadas nas margens dos cursos d'água e em torno das nascente tiveram alteração no seu uso, já que em nenhuma das propriedades pesquisadas existia vegetação nativa nessas áreas.

R. Árvore, Viçosa-MG, v.32, n.2, p.269-278, 2008
- A vegetação nativa nas propriedades resumia-se a pequenos fragmentos localizados nos topos dos morros.

- A aplicação da Lei 14.309/02, que dispõe sobre a legislação florestal no Estado de Minas Gerais, eliminou a necessidade de efetivação da ARL na maioria das propriedades estudadas, por permitir que as APPs fossem computadas para cálculo das ARLs.

\section{REFERÊNCIAS}

BRASIL. Leis e Decretos. Lei Federal no 4.771, de 15 de setembro de 1965. Institui o Novo Código Florestal Brasileiro. Brasília: 2002.

BRASIL. Leis e Decretos. Resolução CONAMA n ${ }^{\circ}$ 303, de 20 de Março de 2002, dispõe sobre as áreas de preservação permanente. Brasília: 2002.

COMITÊ PARA INTEGRAÇÃO DA BACIA DO RIO PARAIBA DO SUL - CEIVAP. Disponível em: http://www.ceivap.org.br/organismo_2_2.php. Acesso em: 26 de jul. de 2005.

\section{INSTITUTOBRASILEIRODEGEOGRAFIAE}

ESTATÍSTICA - IBGE. Estabelecimentos por grupos de área total, segundo municípios - Minas Gerais.

Disponível em: http://www.ibge.gov.br/home/estatistica/ economia/agropecuaria. Acesso em: 28 set. de 2005.

MARCONI, M. A.; LAKATOS, E. M. Técnicas

de pesquisa: planejamento e execução

de pesquisas, amostragens e técnicas

de pesquisas, elaboração, análise e

interpretação de dados. 5.ed. São Paulo: Atlas, 2002.

MINAS GERAIS. Lei 14.309 de 19 de junho de 2002 - Dispõe sobre as políticas florestal e de proteção à biodiversidade no Estado de Minas Gerais. Acesso em dezembro de 2005. Disponível em: http:// www.ief.mg.gov.br/legislação/leisdecret.htm

MINAS GERAIS. Decreto 43.710 de 8 de janeiro de 2004 - Regulamenta a Lei 14.309 de 19 de junho de 2002 que dispõe sobre as políticas florestal e de proteção à biodiversidade no Estado de Minas Gerais. Acesso em dezembro de 2005. Disponível em: http:// www.ief.mg.gov.br/legislação/leisdecret.htm

OLIVEIRA, P. R. S. Diagnóstico e indicadores de sustentabilidade em fomento florestal no Estado do Espírito Santo. 2003. 127f. Dissertação (Mestrado em Ciência Florestal) - Universidade federal de Viçosa, Viçosa, MG, 2003.

RIBEIRO, C. A. A. S. et al. O desafio da delimitação de áreas de preservação permanente. Revista Árvore, v.29, n.2, p.203-212, 2005. 